\title{
Informasjonskilder for kunnskapsbasert praksis
}

\author{
Sari Susanna Ormstad ${ }^{1}$ og Hege Underdal ${ }^{2}$ \\ 1) Seksjon for spesialisthelsetjenesten, Nasjonalt kunnskapssenter for helsetjenesten \\ 2) Helsebiblioteket, Nasjonalt kunnskapssenter for helsetjenesten \\ E-post: sari.susanna.ormstad@kunnskapssenteret.no Telefon 46400484
}

\section{SAMMENDRAG}

Fremveksten av kunnskapsbasert praksis har ført til økt fokus på å gjøre forskningsbasert kunnskap lettere tilgjengelig. 6S-pyramiden, som er utviklet av McMaster University i Canada, er en modell som viser hvordan helsefaglig forskning kan plasseres på seks ulike nivåer, avhengig av graden av oppsummering og kvalitetsvurdering. Modellen kan brukes som et verktøy når man skal velge relevante søkekilder.

Den mest sammenstilte kunnskapen om ulike tilstander og sykdommer finner man i kliniske oppslagsverk og kunnskapsbaserte retningslinjer. De har som formål å tilby kunnskapsbaserte og oppdaterte anbefalinger om diagnostisering, behandling og oppfølging av spesifikke utvalgte tilstander i lettlest format.

Om man søker etter litteratur til bruk i utarbeidelsen av fagprosedyrer, retningslinjer, systematiske oversikter eller lignende oppsummeringer, må det utføres søk i bibliografiske databaser og andre lignende kilder. Man bør først lete etter systematiske oversikter og eventuelt utvide søket etter primærstudier dersom man ikke finner oppdaterte, relevante systematiske oversikter.

Helsebiblioteket.no er et offentlig finansiert nettbibliotek som gir gratis tilgang til norske og internasjonale kunnskapskilder. Helsebiblioteket kjøper tilgang til lisensbelagte ressurser som kliniske oppslagsverk, databaser og tidsskrifter. Mange av kildene nevnt i denne artikkelen inngår i Helsebibliotekets samling. I tillegg er nettsiden en delingsplattform for norske retningslinjer, prosedyrer og annet stoff som utvikles i det offentlige helse-Norge.

\section{Ormstad SS, Underdal H. Information sources for evidence-based practice. Nor J Epidemiol 2013; 23 (2): 221-224.}

\section{ENGLISH SUMMARY}

The development of evidence-based practice has led to an increased focus on making research-based evidence easily accessible. The $6 \mathrm{~S}$ model, developed by McMaster University in Canada, is a model that describes how health-related research evidence can be sorted out on six different levels. The higher one comes in the model, the more summarized and quality-assured the evidence is. The $6 \mathrm{~S}$ model can be used as a tool when selecting relevant sources for the literature search.

The most compiled evidence on various conditions and diseases can be found in evidence-based point of care tools and clinical practice guidelines. They are designed to offer comprehensive and up-to-date recommendations on diagnosis, treatment and monitoring of specific conditions condensed into easily digestible formats.

When looking for relevant research evidence to be included in clinical procedures, clinical practice guidelines, systematic reviews and other evidence syntheses, one should conduct searches in bibliographic databases and other similar sources. One should first try to find systematic reviews or similar evidence syntheses written about the topic of interest, and expand the search for primary studies only if no relevant up-to-date systematic reviews are available.

The Norwegian Electronic Health Library (helsebiblioteket.no) is a publicly funded e-library that provides free access to many Norwegian and international sources. The Norwegian Electronic Health Library purchases access to licensed resources, such as clinical reference works, databases, and journals. Many of the sources mentioned in this article are included in the collection of the Electronic Health Library. In addition, the e-library is a sharing platform for Norwegian clinical practice guidelines, clinical procedures, and other materials developed in the public health care system in Norway.

This is an open access article distributed under the Creative Commons Attribution Licence, which permits unrestricted use, distribution, and reproduction in any medium, provided the original work is properly cited.

\section{INTRODUKSJON}

Systematisk innhenting av forskningslitteratur innebærer at man prøver å identifisere mest mulig forskning om et gitt emne i relevante databaser og kilder. Hvilke kilder man bør søke i, avhenger blant annet av hva slags forskningsspørsmål det er snakk om (effekt av tiltak, diagnostikk, årsakssammenhenger osv.), temaet, formålet med søket (sluttproduktet) og tilgangen til databaser og kilder (1). Tiden og ressursene man har til rådighet for å utføre søket er også avgjørende.

Spørsmål, studiedesign og valg av kilder henger nøye sammen fordi type forskningsspørsmål har betydning for hva slags forskning man bør lete etter og 
dermed hvilke kilder man bør søke i (1). Man bør vanligvis først prøve å lete etter systematiske oversikter og annen oppsummert kunnskap, og utvide søket til primærstudier først dersom relevante oversikter mangler eller er utdaterte (1).

\section{S-MODELLEN}

Fremveksten av kunnskapsbasert praksis har ført til økt fokus på å gjøre forskningsbasert kunnskap lettere å finne og lese. Mengden av databaser og kilder som gir tilgang til oppsummert forskning og videreformidler forskningsresultater av høy kvalitet, er blitt større. 6Spyramiden, som er utviklet av McMaster University i Canada, er en modell som fremstiller hvordan helsefaglig forskning kan plasseres på seks ulike nivåer, avhengig av graden av oppsummering og kvalitetsvurdering (2). Modellen kan brukes som et verktøy når man skal velge relevante kilder i søk. Figur 1 viser en modifisert versjon av pyramiden.

På bunnen av pyramiden finner man primærstudier. Primærstudier som er kvalitetsvurdert, oppsummert og kommentert, er plassert på nivået ovenfor. Ovenfor disse igjen finner man systematiske oversikter og kvalitetsvurderte systematiske oversikter. På nest øverste nivå finnes kliniske oppslagsverk og kunnskapsbaserte retningslinjer som innhenter og sammenstiller kunnskap fra alle de fire nivåene under. Toppen av pyramiden er reservert elektroniske beslutningsstøttesystemer, hvor den enkelte pasientens symptomer eller tilstand automatisk lenkes til kilder til forskningsbasert kunnskap slik at klinikeren får opp råd og anbefalinger direkte i den elektroniske pasientjournalen. I Norge har man per i dag tilgang til kilder på alle nivåene, unntatt det aller øverste.

Man bør alltid begynne et søk så høyt oppe i 6S-pyramiden som mulig (2).

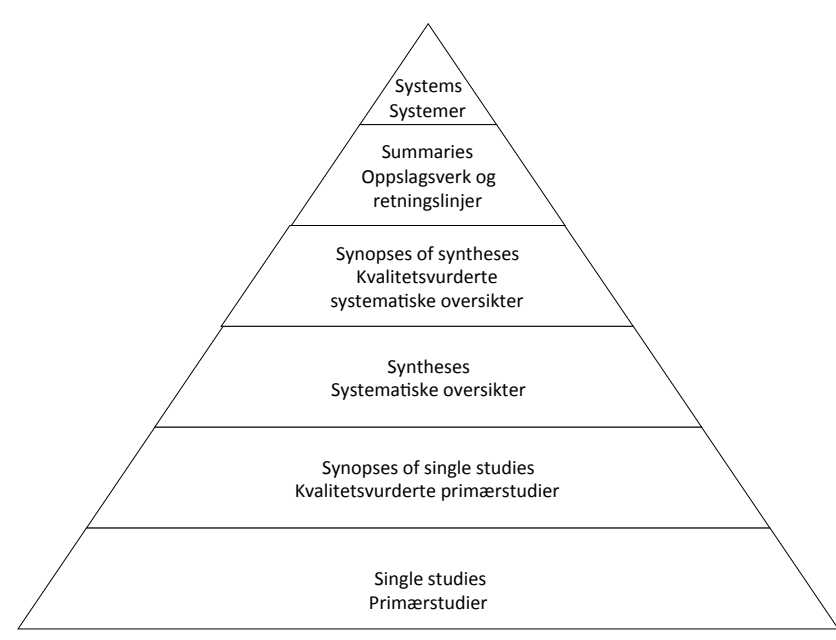

Figur 1. 6 S-pyramide, modifisert etter DiCenso et al., 2009.

\section{KLINISKE OPPSLAGSVERK OG RETNINGSLINJER}

Den mest sammenstilte kunnskapen om ulike tilstander og sykdommer finner man i kliniske oppslagsverk og kunnskapsbaserte retningslinjer. Kliniske oppslagsverk, som BMJ Best Practice, UpToDate og Dynamed, er utviklet for klinikere til bruk i møtet med pasienten. De har som formål å tilby kunnskapsbaserte, oppdaterte anbefalinger om diagnostisering, behandling og oppfølging av spesifikke tilstander - i et lettfordøyelig format. Man skal likevel være klar over at tiden det tar å oppdatere og inkorporere nye forskningsresultater varierer betraktelig mellom de ulike kliniske oppslagsverkene $(3,4)$. Det brukes også ulike metoder for å identifisere og kvalitetsvurdere ny forskning (5).

Utenlandske retningslinjer kan identifiseres i store internasjonale databaser som Guidelines International Network (G-I-N) og National Guideline Clearinghouse (NGC). Norske retningslinjer er samlet i Helsebibliotekets retningslinjedatabase. Disse kan også ofte finnes på utgivernes egne hjemmesider. Det er viktig å være oppmerksom på at ikke alle retningslinjer man finner i de ulike kildene er kunnskapsbaserte og oppdaterte (2).

\section{KILDER TIL SYSTEMATISKE OVERSIKTER}

Om man leter etter litteratur til bruk i utarbeidelsen av fagprosedyrer, retningslinjer eller lignende oppsummeringer, kan man med fordel bruke kliniske oppslagsverk, blant annet for å skaffe seg en oversikt over litteraturomfanget. Ofte bør man i tillegg fortsette nedover i pyramiden og utføre søk etter systematiske oversikter, og eventuelt utvide søket etter primærstudier dersom man ikke finner relevante systematiske oversikter eller disse er utdaterte.

En kvalitetsvurdert systematisk oversikt gir leseren en oppsummering av oversikten, samt at den ofte kommenterer på kvaliteten av oversikten og sier noe om resultatenes anvendelighet i praksis. Database of Abstracts of Reviews of Effects, som er tilgjengelig via The Cochrane Library, publiserer slike strukturerte sammendrag av kvalitetsvurderte oversikter.

Om man vil lese fullstendige systematiske oversikter, eller om man ikke har funnet noen kvalitetsvurderte systematiske oversikter, finnes det flere databaser å søke i. Eksempler er Cochrane Database of Systematic Reviews (CDSR) og Health Technology Assessment (HTA) Database, Physiotherapy Evidence Database (PEDro), Occupational Therapy Systematic Evaluation of Evidence (OTseeker) og The Campbell Library (om tiltak som gjelder utdanning, sosial velferd og kriminalforebygging). MedNytt er en norsk database som videreformidler oversikter over helt nye metoder som ikke er rutinemessig i bruk i norsk helsevesen. 


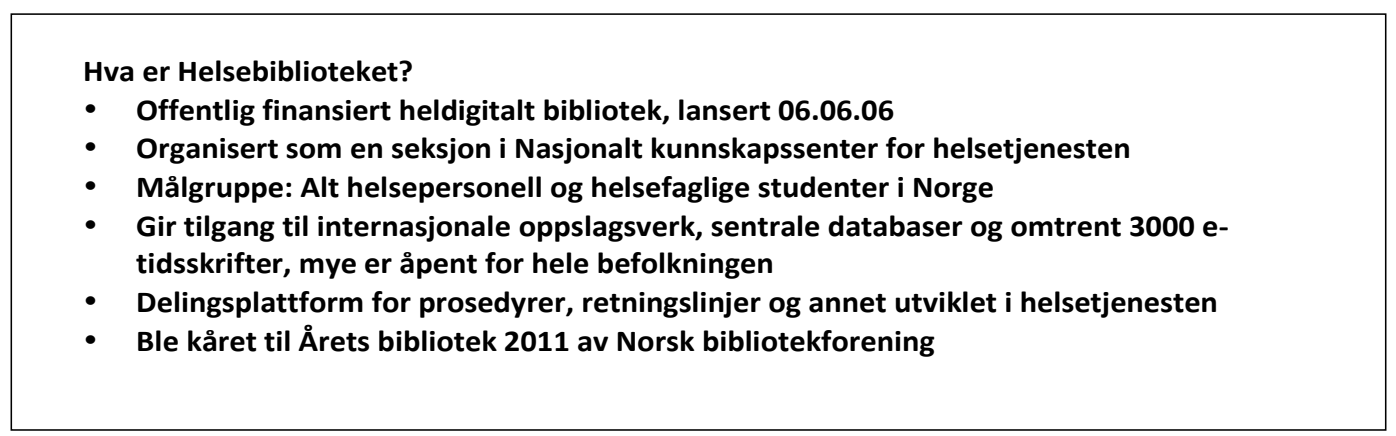

Figur 2. Faktaboks om Helsebiblioteket.

\section{KILDER TIL PRIMARSTUDIER}

Om man ikke finner systematiske oversikter for temaet man er interessert $\mathrm{i}$, går man videre og søker etter primærstudier. Tidsskrifter som ACP Journal Club, Evidence-Based Medicine og Evidence-Based Nursing publiserer oppsummeringer av primærstudier, med en vurdering av kvaliteten på den aktuelle studien. Slike tidsskrift er indeksert i generelle medisinske og helsefaglige databaser, som MEDLINE.

Ingen bibliografisk database er komplett (1). Det varierer hvilke tidsskrifter som inngår, typer av artikler som inkluderes, språk osv. Eksempelvis er både PubMed/MEDLINE og Embase internasjonale databaser, men de har slagside mot tidsskrifter utgitt henholdsvis i USA og Europa.

I tillegg til store, generelle medisinske og helsefaglige databaser, som PubMed/MEDLINE og Embase, kan man vurdere å søke etter primærstudier i fagspesifikke databaser. Eksempler på slike er PsycINFO innen psykisk helse, og Cumulative Index to Nursing and Allied Health (CINAHL) innen sykepleie og tilgrensende fag. I tillegg finnes det databaser som er begrenset til spesifikke typer av studier. Ett eksempel er Cochrane-samarbeidets register over kontrollerte studier, Cochrane Central Register of Controlled Trials (CENTRAL). Eksempler på databaser dedikert til helseøkonomiske evalueringer er NHS Economic Evaluation Database (NHS EED) og Health Economic Evaluations Database (HEED).

I følge Chan et al. blir cirka halvparten av kliniske studier aldri publisert (6). Studier som publiseres i tidsskrift har også tendens til å være større og vise større behandlingseffekter enn upubliserte studier eller grålitteratur (litteratur som ikke er blitt publisert av kommersielle utgivere) $(6,7)$. Det finnes flere registre som inneholder informasjon om pågående og avsluttede studier. World Health Organization's International Trials Registry Platform Search Portal søker på tvers av flere nasjonale og internasjonale registre og er en sentral kilde for slik informasjon. I tillegg til studieprotokoller, inneholder noen registre også studieresultater, for eksempel ClinicalTrials.gov. Grålitteratur kan være vanskelig å finne fram til, men det finnes databaser som registrerer "grått materiale", for eksempel OAIster.

\section{Helsebiblioteket}

Helsebiblioteket.no er et offentlig finansiert nettbibliotek som gir gratis tilgang til norske og internasjonale kunnskapskilder på Internett. Helsebiblioteket kjøper tilgang til lisensbelagte ressurser som kliniske oppslagsverk, databaser og tidsskrifter. Mange av kildene nevnt ovenfor inngår i Helsebibliotekets samling. I tillegg er nettsiden en delingsplattform for norske retningslinjer, fagprosedyrer og annet stoff som utvikles i det offentlige helse-Norge.

Målgruppen for Helsebiblioteket er alt helsepersonell i Norge, samt studenter innen medisin- og helsefag. Helsebiblioteket samarbeider tett med fagbibliotekene ute i sykehusene og på undervisningsinstitusjonene. Innholdet i Helsebiblioteket er en grunnpakke som lokale bibliotek kan bygge videre på ved å tegne ytterligere abonnement på databaser og spesialtidsskrifter.

Via Helsebiblioteket har man tilgang til oppslagsverkene BMJ Best Practice og UpToDate. Her finner man oppsummert kunnskap og anbefalinger for diagnostisering og behandling. I Helsebibliotekets norske retningslinjesamling finner man alt fra nasjonale retningslinjer fra Helsedirektoratet, til veiledere fra ulike spesialistforeninger og fagmiljøer rundt om i landet. Gjennom Guidelines International Network (G-I-N) gir Helsebiblioteket dessuten tilgang til mange utenlandske retningslinjer. Under "Prosedyrer" finner man kunnskapsbaserte fagprosedyrer utarbeidet innenfor Nasjonalt nettverk for fagprosedyrer (fagprosedyrer.no). Disse er utviklet etter en fast metode for så å sikre høyest mulig kvalitet, og deles med resten av helsetjenesten via Helsebiblioteket.no.

Fra forsiden kan man klikke seg videre til sentrale databaser innenfor medisin- og helsefag. "Oppsummert forskning" gir en oversikt over databaser som er relevante for søk etter systematiske oversikter og lignende oppsummeringer. Under "Databaser" finner man ytterligere kilder som kan brukes for søk etter primærstudier, herunder MEDLINE, Embase og CINAHL. Når man har utført søk i en database, kan man gå videre til fulltekstartikler fra trefflisten der Helsebiblioteket (eller det lokale bibliotek) har abonnement. I skrivende stund abonnerer Helsebiblioteket på omtrent 3000 tidsskrifter i fulltekst. 
I tillegg finnes det noen tjenester i Helsebiblioteket som kan hjelpe brukerne å holde seg oppdatert innenfor sitt fagfelt, som McMaster PLUS-tjenesten. Dette er en nyhetstjeneste man kan abonnere på for å motta informasjon på e-post om nye studier innen et spesifikt felt.

Mange av ressursene i Helsebiblioteket er tilgjengelige for hele befolkningen gjennom nasjonal IP-gjenkjenning. Det betyr at alle som går ut på Internett via en norsk IP-adresse kommer rett inn på flere av ressursene, uten å måtte gå via Helsebiblioteket.no, og uten å logge inn. Dette gjelder eksempelvis oppslagsverkene BMJ Best Practice og UpToDate, og tidsskrifter som $J A M A$, The Lancet og New England Journal of Medicine.

I noen få tilfeller har det ikke vært økonomisk mulig å inngå nasjonale avtaler, og tilgangen er da forbe- holdt helsepersonell og studenter. I disse tilfellene må man enten gå ut på nett fra en institusjon som er registrert i Helsebibliotekets system, eller logge inn med personlig brukernavn og passord, for å få tilgang. Det er gratis å opprette brukernavn på Helsebiblioteket.no.

\section{VIDERE LESING}

Videre lesing og omfattende oversikter over kilder (bibliografiske databaser, grålitteraturkilder, registre over pågående og avsluttede studier m.m.) finnes blant annet i Cochrane Handbook for Systematic Reviews of Interventions (8), Cochrane Handbook for Systematic Reviews of Diagnostic Test Accuracy (9), Grey Matters: a practical search tool for evidence-based medicine (10) og Health Technology Assessment on the Net International (11).

\section{REFERANSER}

1. Nasjonalt kunnskapssenter for helsetjenesten. Slik oppsummerer vi forskning. Håndbok for Nasjonalt kunnskapssenter for helsetjenesten. 3.2. reviderte utg. Oslo: Nasjonalt kunnskapssenter for helsetjenesten, 2013.

2. DiCenso A, Bayley L, Haynes RB. ACP Journal Club. Editorial: Accessing preappraised evidence: fine-tuning the 5S model into a 6S model. Ann Intern Med 2009; 151 (6): JC3-2,JC3-3.

3. Banzi R, Cinquini M, Liberati A, Moschetti I, Pecoraro V, Tagliabue L, Moja L. Speed of updating online evidence based point of care summaries: prospective cohort analysis. BMJ 2011; 343: d5856.

4. Jeffery R, Navarro T, Lokker C, Haynes RB, Wilczynski NL, Farjou G. How current are leading evidencebased medical textbooks? An analytic survey of four online textbooks. J Med Internet Res 2012; 14 (6): e175.

5. Shurtz S, Foster MJ. Developing and using a rubric for evaluating evidence-based medicine point-of-care tools. J Med Libr Assoc 2011; 99 (3): 247-254.

6. Chan AW. Out of sight but not out of mind: how to search for unpublished clinical trial evidence. BMJ 2012; 344: d8013.

7. Hopewell S, McDonald S, Clarke M, Egger M. Grey literature in meta-analyses of randomized trials of health care interventions. Cochrane Database Syst Rev 2007; 2: MR000010.

8. Lefebvre C, Manheimer E, Glanville J. Chapter 6: Searching for studies. In: Higgins JPT, Green S (Eds). Cochrane handbook for systematic reviews of interventions. Chichester: Wiley-Blackwell, 2008: 95-150.

9. de Vet HCW, Eisinga A, Riphagen II, Aertgeerts B, Pewsner D. Chapter 7: Searching for studies. In: Cochrane handbook for systematic reviews of diagnostic test accuracy, Version 0.4. The Cochrane Collaboration, 2008. [oppdatert 30. sep. 2008; lest 22. mar. 2013]. Tilgjengelig fra: http://srdta.cochrane.org/sites/ srdta.cochrane.org/files/uploads/Chapter07-Searching-\%28September-2008\%29.pdf.

10. Canadian Agency for Drugs and Technologies in Health, Information Services. Grey matters: a practical search tool for evidence-based medicine. Ottawa: CADTH, 2013.

11. Institute of Health Economics, Osteba, AUnETS. Health Technology Assessment on the Net International: 2012. Edmonton AB: Institute of Health Economics, 2012. 